\section{The fate of (ultra)trace elements along a steep redox gradient in mesoscale laboratory lysimeters}

\section{MARCUS BÖHM ${ }^{1}$, DANIEL JARA-HEREDIA ${ }^{2}$, ARNO MÄRTEN ${ }^{1}$, FRANCESCA QUINTO ${ }^{3}$ AND THORSTEN SCHÄFER ${ }^{1}$}

${ }^{1}$ Friedrich Schiller University Jena

${ }^{2}$ Friedrich-Schiller University Jena

${ }^{3}$ Karlsruhe Institute of Technology

Presenting Author: marcus.boehm@uni-jena.de

In the frame of the long-term safety of a deep geological repository for high-level radioactive waste, the possible transport of radionuclides into the geosphere and their accumulation in the far field up to the biosphere must be considered. Here, a mesoscale laboratory lysimeter experiment with four different natural agricultural top soil substrates was set up within the BMBF funded project TransLARA (www.trans-lara.de) to investigate the upward transport of long-lived radionuclides and their homologues (e.g. rare earth elements) from groundwater through the unsaturated zone and ultimately into crop plants under different climate conditions.

The packed lysimeters were placed in a dark climate chamber at $10.5^{\circ} \mathrm{C}$. Grimsel-Test-Site groundwater carrying actinide tracers ${ }^{233} \mathrm{U},{ }^{237} \mathrm{~Np},{ }^{242} \mathrm{Pu}$ and ${ }^{243} \mathrm{Am}$ at $\leq \mathrm{ppq}$ levels (Quinto et al., 2015, Quinto et al., 2017) was continuously fed for over 750 days to the subsoil and maintained at a constant level in the evaporation driven systems. After about 200 days, the formation of a redox interface at the capillary fringe was observed by insitu Eh probes and precisely located with a sub-mm resolution with $\mathrm{CO}_{2}$ - and $\mathrm{O}_{2}$-chemical optical sensor foils (VisiSens TD) (image A). The precipitation horizon with redoximorphic features was also observable through the transparent lysimeter wall (image B). Additionally, after about 500 days, an injection experiment with $\mathrm{Br}^{-}$and $\mathrm{Cl}^{-}$as conservative tracers and several target species such as $\mathrm{SeO}_{4}{ }^{2-}$ and $\mathrm{I}^{-}$was initiated. Pore water samples were periodically analyzed with ICP-MS/AES, ion chromatography, nanoparticle tracking analysis (NTA) and for DOC at three different depths (purple squares in image). Along the physicochemical gradient with $\Delta$ Eh of $500-700 \mathrm{mV}$ in a $7 \mathrm{~cm}$ soil section, a change in porewater water composition was detectable. Conservative tracers showed a recovery of $>90 \%$, redox sensitive tracers showed significant lower recovery compared to injected concentrations. I' breakthrough was nearly identical under reducing conditions, whereas recoveries decreased to $\approx 24 \%$ under high Eh values (image C). Other species as well as AMS measurements of pore waters and solid phase analysis will be discussed in the presentation.

[1] Quinto et al. (2015), Anal Chem 87, 5766-73.

[2] Quinto et al. (2017), Anal Chem 89, 7182-89.

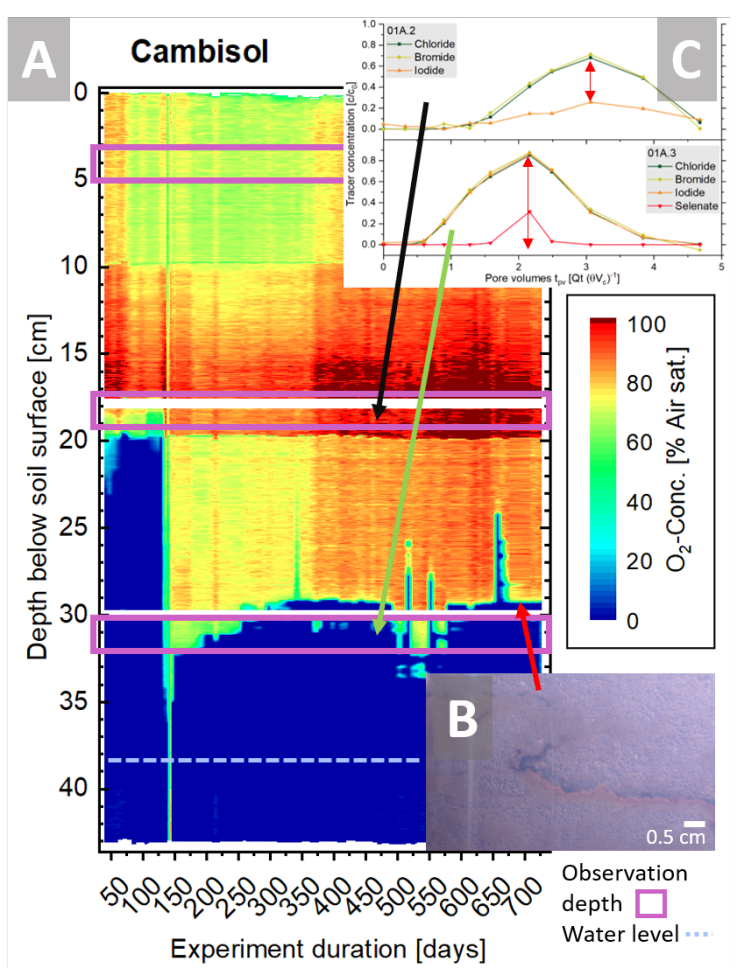

